\title{
A CORPOREIDADE "DAS PRETAS": IDENTIDADE E CONSUMO NAS ESTRATÉGIAS POLÍTICAS DE EMPODERAMENTO EM UM COLETIVO DE MULHERES NEGRAS NA CIDADE DE VITÓRIA
}

\author{
THE CORPOREITY OF "DAS PRETAS": IDENTITY AND CONSUMPTION IN \\ POLITICAL EMPOWERMENT STRATEGIES IN A BLACK WOMEN'S COLLECTIVE \\ IN THE CITY OF VITÓRIA, ES
}

\author{
LA CORPOREIDAD "DAS PRETAS": IDENTIDAD Y CONSUMO EN LAS \\ ESTRATEGIAS POLITICAS DE EMPODERAMIENTO EN UN COLECTIVO DE \\ MUJERES NEGRAS EN LA CIUDAD DE VITÓRIAVES
}

\section{Gustavo Marchetti Carneiro*, Ivan Marcelo Gomes*}

\begin{abstract}
Palavras chave: Corpo humano. Mulheres. Grupo com ancestrais do continente africano. Etnicidade.

Resumo: 0 presente texto apresenta elementos de uma pesquisa realizada junto a um coletivo de mulheres negras atuantes na cidade de Vitória (ES), denominado Das Pretas. $O$ texto tem como objetivo interpretar os modos de subjetivação e formação deste coletivo a partir das relações entre corpo, consumo e identidades políticas. A pesquisa se caracteriza como qualitativa e teve na observação participante sua principal estratégia. Utilizamos o diário de campo, entrevistas semiestruturadas e informações disponibilizadas em páginas virtuais vinculadas ao coletivo para a produção dos dados. A partir daí, foram elaboradas categorias de análise como estratégia interpretativa para a compreensão desses processos no coletivo e sua relação com o corpo. Consideramos que o trabalho possibilita reflexões sobre a corporeidade negra no Brasil contemporâneo ao destacar as ideias, as propostas e as ações deste coletivo, bem como oferece algumas críticas ao discurso sobre o corpo modelo identificado durante a pesquisa.
\end{abstract}

Keywords: Human Body. Women. African Continental Ancestry Group. Ethnicity.

Palabras clave: Cuerpo humano. Mujeres.

Grupo con ancestrales del continente africano Etnicidad.

Abstract: This paper presents elements of a study conducted with a black women's collective that operates in the city of Vitória, ES, called Das Pretas (Black Women's). It aims to interpret modes of subjectivation and construction of the group based on relations between body, consumption and political identities. It is a qualitative research with participant observation as its main strategy. To generate data, we used a field diary, semi-structured interviews, and information available on websites linked to the Collective. Then, categories of analysis were built as an interpretative strategy to understand those processes within the collective and their relationship to the body. This work allows reflections about black corporeity in today's Brazil by highlighting that collective's ideas, proposals and actions as well as by offering some criticism to the discourse about the model body found during the research.

Resumen: El texto presenta elementos de una investigación realizada junto a un colectivo de mujeres negras actuantes en la ciudad de Vitória (ES), denominado "Das Pretas". Tiene como objetivo interpretar los modos de subjetivación y formación de este colectivo a partir de las relaciones entre cuerpo, consumo e identidades políticas. La investigación se caracteriza como cualitativa y tuvo como principal estrategia la observación participante. Utilizamos el diario de campo, entrevistas semiestructuradas e informaciones disponibles en páginas virtuales vinculadas al colectivo para la producción de los datos. Sobre esa base, fueron elaboradas categorías de análisis como estrategia interpretativa para la comprensión de esos procesos en el colectivo y su relación con el cuerpo. Consideramos que el trabajo posibilita reflexiones sobre la corporeidad negra en el Brasil contemporáneo al destacar las ideas, las propuestas y las acciones de este colectivo, así como ofrece algunas críticas al discurso sobre el cuerpo modelo identificado durante la investigación.
*Universidade Federal do Espírito Santo. Vitória, ES, Brasil. E-mail: gumarchetti@gmail.com; ivanmgomes@hotmail.com

Recebido em: 18-07-2017 Aprovado em: 11-05-2018

DOI: https://doi.org/10.22456/1982-8918.75059 (c) (i) (8) Licence (1) Creative Commom 


\section{INTRODUÇÃOO}

O presente texto traz elementos de uma pesquisa que teve como objetivo interpretar os modos de subjetivação e formação desenvolvidos no interior do coletivo/Instituto Das Pretas ${ }^{1}$, enfocando as relações entre corpo, consumo e identidade política no interior dele. Com isso almejamos identificar os usos do corpo na cultura contemporânea, especificamente no que aqui identificamos como Geração Tombamento², no qual a noção de corporeidade negra se fundamenta num discurso que vai desde o reconhecimento de sua negritude à inserção no mercado (seja como trabalhador ou consumidor).

Como forma de aproximação do objeto da pesquisa, identificamos que as reivindicações históricas do Movimento Negro dão ênfase maior ao corpo e cultura negra a partir da década de 1970. Até este momento, a identidade negra, em território nacional, enfrentava os processos de construção de uma identidade brasileira, marcada por uma perspectiva racialista ${ }^{3}$ (KERN, 2015; MUNANGA, 1999), conjugando o povo brasileiro como uma raça miscigenada, construída a partir do branco, negro e índio, sob uma noção de democracia racial ${ }^{4}$ que construiu o imaginário social e intelectual no Brasil, tornando-se mito fundante para a constituição do povo brasileiro, velando assim as diferenças nas relações sociais no país.

A resistência do povo negro demandava, portanto, a criação de outros referenciais a fim de afirmar sua diferenciação social e fortalecer a crítica à discriminação racial existente no Brasil. A negritude ${ }^{5}$, nos anos 1970, passa a ser um referencial afirmativo para o povo negro. 0 desafio do negro brasileiro consiste nesse período em tomar consciência de sua negritude, em orgulhar-se de ser negro. Sem nos alongarmos aqui sobre os momentos históricos, afirmamos a continuidade dos períodos presente no Movimento Negro, identificando inclusive no coletivo de mulheres aqui apresentado marcas de uma história contínua da militância negra.

Partindo das reflexões de Mattos (2015), que pesquisou algumas das comunidades virtuais de empoderamento feminino negro e discorreu sobre a estética negra e o empoderamento a partir de estudos autobiográficos, compreendemos esse movimento de afirmação identitária que se reforça na juventude negra, a partir de sua ênfase numa "estética afro-diaspórica". Afro por sua vinculação com a ancestralidade africana, e diaspórica por se construir no interior de reflexões pós-coloniais, considerando as ações das negras e dos negros dispersos (da África para o mundo ocidental, desde o Atlântico). Mattos define o termo:

[...] é o movimento em que homens, mulheres, homossexuais, transexuais, gays e também as crianças negras adotam variações para os seus corpos e cabelos

\footnotetext{
1 Neste trabalho o grupo estudado será apresentado como Coletivo, embora seja também referido como um instituto (organização). Como será demonstrado mais à frente, as mulheres que dirigem o instituto o descrevem como um coletivo, em decorrência do modo como iniciou-se, e parecem extrair daquele momento os fundamentos para a reflexão que molda suas atividades enquanto instituto.

2 Stephanie Ribeiro, em artigo publicado na revista eletrônica Trip, em 25 de julho de 2016, defende que a "[...] geração tombamento é um mix de afirmação da sua ancestralidade com (re)criação de uma possibilidade histórica. Isso a aproxima do contexto afrofuturista - movimento que utiliza a música, as artes e a moda para fazer uma mistura da cultura africana com tecnologia, ciência e futuro. $\mathrm{O}$ afro como possibilidade, como futuro, enfim, como algo positivo e orgulhoso". Disponível em: <http://revistatrip.uol.com.br/tpm/stephanie-ribeiro-escreve-sobre-geracaotombamento-e-afrofuturismo>. Acessado em: 16/02/17.

3 "A classificação da humanidade em raças hierarquizadas desembocou numa teoria pseudocientífica, a raciologia, que ganhou muito espaço no início do século XX. Na realidade, apesar da máscara científica, a raciologia tinha um conteúdo mais doutrinário do que científico, pois seu discurso serviu mais para justificar e legitimar os sistemas de dominação racial do que como explicação da variabilidade humana" (MUNANGA, 2003, p. 5). 4 Visto como um mito fundador da nacionalidade brasileira (encontrando em Gilberto Freyre seu principal expoente), o conceito de democracia racial sofreu duros ataques de ativistas negros, sendo analisado como instrumento ideológico dominante.

50 discurso de negritude, na opinião de Munanga, nasce do "sentimento de frustração dos intelectuais negros por não terem encontrado no humanismo ocidental todas as dimensões de sua personalidade" (MUNANGA, 2012, p. 63). Esta, no entanto, foi uma angústia dos negros intelectuais, que se lançam no esforço de reestruturar um arcabouço teórico que garanta aos negros uma identidade comum (sobre 0 movimento de negritude, ver DOMINGUES, 2005).
} 
criando e recriando penteados de matriz africana, usando e abusando do tamanho dos fios, formas e cores, assumindo sua corporeidade nesse contexto de mudanças sociais, lutas históricas e hibridismo estético (MATTOS, 2015, p. 38).

No interior dessa afirmação da corporeidade negra, identificamos as marcas de uma geração de jovens negras e negros, fortemente ligados às redes sociais, produzindo e reproduzindo moda e fomentando a atividade cultural na sociedade. Assim, aproximamo-nos da Geração Tombamento, reconhecendo nesta não uma ruptura com o Movimento Negro, mas o resgate e interpretação de algumas de suas reivindicações, tendo como referência a corporeidade negra que toma materialidade com mais força, desde os anos 2000, em diferentes espaços sociais, como nos salões e produtos voltados ao afro.

Acreditamos que o coletivo Das Pretas se insere nesse movimento de juventude negra, buscando sua inspiração e até mesmo identificando-se como parte dessa geração que vem para "tombar". As ênfases do IDP na afirmação da corporeidade negra e na ancestralidade indicam tais aproximações. Essa Geração Tombamento possui suas fontes de inspiração nos movimentos afropunk ${ }^{7}$ e fashion rebels ${ }^{8}$, com forte perspectiva afrofuturista ${ }^{9}$ e ênfase numa estética afrodiaspórica.

Após a apresentação de elementos teóricos que nos contextualizam nesta temática, abordaremos os outros aspectos constituintes do texto destacando a caracterização do IDP as estratégias metodológicas utilizadas na pesquisa. Em seguida, enfocaremos as categorias de análise construídas objetivando formular uma lente interpretativa com a qual seja possível analisar a centralidade do corpo nos discursos e ações do IDP.

\section{SUJEITOS DA PESQUISA}

O coletivo Das Pretas atua, principalmente, na cidade de Vitória, capital do Espírito Santo. As mulheres envolvidas nesse grupo o apresentam como um coletivo, iniciado em 2013, que se institucionaliza em 2015, sob o nome de Instituto Das Pretas ${ }^{10}$.

No artigo segundo do documento de registro do Instituto, consta que é uma...

[...] organização de mulheres negras, que tem por finalidades o compartilhamento do empoderamento às mulheres negras e suas famílias com, essencialmente, 0 resgate à sua ancestralidade, à autoidentificação enquanto afrodescendente e a construção de uma autoestima fortificada e fundamentada.

\footnotetext{
6 Gíria oriunda dos espaços LGBTT, popularizada pela cantora Karol Conka. Aponta para uma chegada impactante e orgulhosa de si, chamando a atenção das demais pessoas.

7 "[...] Em 2003, Matthew Morgan produziu ‘Afro-Punk', o documentário [...]. AFROPUNK evoluiu para uma pedra de toque de um movimento cultural relembrando fortemente os primeiros dias do Hip-Hop. Crianças urbanas alternativas em todo o mundo que se sentiam como outsiders descobriram que eles eram realmente o núcleo de uma comunidade ousadamente inovadora, de rápido crescimento. [...] Em 2005, o primeiro festival anual de AFROPUNK [...]. Descrito pelo New York Times como 'o festival mais multicultural dos Estados Unidos', a palavra AFROPUNK tornou-se sinônimo de comunidade aberta, não conformista e não convencional, colocando a instituição no epicentro da cultura urbana inspirada pela música alternativa". Tradução livre extraída de <http://www.afropunk.com/page/the-movement>. Acesso em: 2 abr. 2017.

8. Movimento de jovens negros na África do Sul, que promovem uma inversão na indústria de moda ao mover a atenção das marcas para o estilo, tornando mais acessível aos que só tem os bazares da cidade como opção de compra.

9 O afrofuturismo constitui-se como um movimento cultural a partir dos anos 1990, embora remeta à revolução cultural dos anos 1960, e faz referência à mitologia e cosmologia africana primitiva, unindo-a à tecnologia, à ciência e ao novo. Isso se manifesta nas artes plásticas, música, literatura e estética (tendo como referência o misticismo, o primitivo e a mitologia africana, além de elementos mood sci-fi, que carregam um tom futurista). Referências podem ser encontradas no seguinte texto: BRASIL, Luiza. Dossiê afrofuturismo: saiba mais sobre o movimento cultural. Em: <http://www.geledes.org.br/dossie-afrofuturismo-saiba-mais-sobre-o-movimento-cultural/\#gs.= tLiGxE>. Acesso em: 11 mar. 2017.

10 Também é possível encontrar a nomenclatura DasPretas.org, ao referir-se ao grupo. No citado trabalho, utilizamos o termo Instituto ou Coletivo Das Pretas, sendo reconhecido sob a sigla IDP.
} 
Atualmente o IDP é uma pessoa jurídica de direito privado, sem fins lucrativos, e duração por tempo indeterminado, como descrito no seu site ${ }^{11}$ :

[...] Em 2013 começamos a nos reunir em volta a discussões de empoderamento estético de mulheres negras. Em 2015, institucionalizamos o INSTITUTO DAS PRETAS.ORG, a primeira organização de Economia Mista Criativa Afro-centrada de protagonismo feminino do país. Em 2016, inauguramos nossa sede. Nossas ações já atingiram, direta e indiretamente, cerca de 2.000 mulheres. Com ações focadas no empreendedorismo e consumo negro, estética \& autoestima, Cultura e Educação, o Das Pretas.org segue seu caminho de maneira autônoma e independente, com recursos vindos de doações e nenhum grande patrocinador. Tendo a transformação pelo Empoderamento coletivo como lema e o Ubuntu ${ }^{12}$ como principal fundamento, o DAS PRETAS.ORG segue agregando pessoas ao longo do caminho e a perspectiva é que todos os espaços sejam ocupados.

Conforme as informações disponíveis no sitedo IDP, o coletivo possui aproximadamente cem mulheres associadas em diversas cidades do estado. Seu principal modo de ação consiste na formação de mulheres negras, por meio de palestras e encontros de cunho mais "intimista".

Os projetos idealizados pelo coletivo acabaram por fazer surgir a necessidade de sua institucionalização. A instituição é vista pela diretoria do IDP como um meio de realização dos anseios do coletivo, de concretização de seus projetos, os quais apresentaremos a seguir.

Começaremos pelo Encontro Das Pretas, que é um evento aberto ao público geral e de entrada gratuita. $O$ Encontro contém duas atividades principais: palestras (discussões, bate-papos, etc.) e estandes de vendas. 0 seu principal objetivo é incentivar o resgate da consciência negra por meio de ações que afirmem a estética afro, refletindo sobre aspectos desafiadores para os negros no mundo contemporâneo.

Como consequência do projeto anterior, surgiu o Das Pretas Colab Store, a loja colaborativa do IDP, sendo um ponto permanente para a exposição dos produtos de afroempreendedores capixabas e, também, de outros estados. Localiza-se na sede do IDP. Em sua descrição no site oficial, ressalta a ligação com a memória do povo negro, por meio de "toda sorte de produtos" capazes de conectar a consumidora à estética ancestral.

Outro projeto do IDP é o Quilombinho. É uma colônia de férias de conteúdo afrocentrado. Conforme a descrição no site $^{13}$, o Quilombinho visa:

Proporcionar às crianças negras um espaço de trocas e convivência, [...], promovendo diálogos sobre a negritude e oficinas de autorreconhecimento, [...] que resgatem a cultura afro-brasileira e empoderem as crianças negras a partir do conhecimento e reconhecimento da história e trajetória de seus ancestrais.

O quarto projeto é o Bekoo Das Pretas, uma festa organizada pelo coletivo e que tem por objetivo ser um espaço de integração e fortalecimento da cultura negra urbana. Em uma postagem no blog Alma Preta, uma das componentes do coletivo afirma que a ideia do Bekoo

[...] é muito simples, música de preto, em bairro de preto, entrada barata, bebida mais barata ainda e um show de beleza e aconchego em um mesmo local. [...]

11 Disponivel em: <www.daspretas.org $>$. Acesso em: 16 jul. 2016.

12 "[...] Ubuntu é uma palavra-conceito que, nas línguas africanas, zulu e xhosa, significa: "Sou quem sou por aquilo que todos somos". Ela exprime o reconhecimento de um vínculo universal de compartilhamento que conecta toda a humanidade, no sentido de sermos pessoas através de outras pessoas" (DISKIN, 2008, p.21). É utilizada no Das Pretas, a fim de demonstrar que o empoderamento das mulheres negras envolvidas somente se realiza na coletividade, daí afirmarem que seja "empoderamento afrocentrado no coletivo".

13 Disponível em: <https://www.daspretas.org/quilombinho>. Acesso em: 10 jun 2016. 
A característica principal da festa é proporcionar um ambiente de liberdade, resistência e muito respeito ${ }^{14}$.

A festa é também uma forma de geração de renda para o coletivo. $O$ dinheiro arrecadado nessas festas é utilizado, conforme informação das integrantes do grupo, para sustentar as demais ações do coletivo.

Deste modo, o IDP é uma organização da sociedade civil, visando à promoção da cultura afrocentrada, com vistas à elevação social e econômica de mulheres negras e suas famílias. É pautada no conceito unitário de empoderamento, que se reforça pela via estéticopolítica e empreendedora na construção de uma identidade que se afirma coletivamente.

\section{CAMINHOS METODOLÓGICOS}

Passemos agora aos caminhos metodológicos percorridos e às categorias analíticas desenvolvidas na pesquisa. $O$ trabalho se caracterizou como uma pesquisa qualitativa, realizada por meio de observação participante (MARCONI; LAKATOS, 1985), concedendo grande valor ao trabalho de campo. $O$ trabalho de campo ocupou nesta pesquisa o lugar de empatia para com o grupo pesquisado, a fim de partilhar suas experiências e deixar-se afetar por elas. Acompanhamos o grupo no período entre julho de 2016 e março de 2017.

Os dados foram produzidos por meio de um diário de campo e entrevistas semiestruturadas, além da utilização de documentos cedidos pelas participantes do coletivo. Por indicação das próprias mulheres da diretoria do IDP, também voltamos os olhares para as mídias sociais, buscando informações em diversos sites, no do coletivo e canais no YouTube.

Do trabalho de campo foram extraídas categorias analíticas que serviram para a avaliação dos objetivos definidos nesta pesquisa. Essas categorias analíticas foram desenvolvidas considerando-se os temas mais recorrentes no IDP, e nos proporcionaram a construção de uma lente interpretativa dos discursos do IDP, possibilitando compreender a ação do coletivo desde a questão da corporeidade.

Buscamos pensar a cidade a partir dos usos vernaculares pelos atores sociais formando sua dinâmica cotidiana (MAGNANI, 2009). Desta forma, observamos o modo de utilização da cidade efetuado pelo coletivo Das Pretas. Optamos pela participação em diferentes ações do coletivo, como, por exemplo: na festa do Bekoo das Pretas, em confraternizações, na loja do IDP, em grupos virtuais, além de integrar serviços de voluntariado em ações como o Quilombinho, buscando encontrar os principais pontos de construção das subjetividades das mulheres envolvidas. Vale ressaltar que o ponto de contato encontrado para a aproximação, é cada vez maior, a identificação com o grupo foi o trabalho voluntário (ao qual o coletivo sempre recorre para suas ações).

O caráter formativo do Das Pretas aponta para uma perspectiva que relatamos como sendo um processo ou escalada na identificação do indivíduo, com a causa do povo negro, a qual vai desde o desenvolvimento de uma relação afetuosa consigo e seu corpo até o fortalecimento econômico de outras mulheres negras. Apontaremos aqui, conforme observado, quatro pilares que foram centrais na constituição e elaboração das categorias e que preconizam a forma de sentir o mundo e a corporeidade. Tais categorias foram denominadas: "Autorreconhecimento", 
"Testemunho", "Visibilidade" e "Afroconsumo". A menção ao corpo negro é parte fundamental na construção discursiva do Das Pretas. Passaremos agora a apresentá-las.

\section{AUTORRECONHECIMENTO}

A categoria de análise denominada Autorreconhecimento é utilizada aqui para abranger os conteúdos presentes na perspectiva utópica ${ }^{15}$ do IDP. 0 termo compreende uma forma de construção utópica que enfatiza a experiência, aquilo que toca a descoberta íntima. 0 afeto atualiza a utopia. É um processo de reconciliação com a própria imagem corporal. Essa reconciliação se dá por meio da utilização de produtos afros e exaltação das características físicas das mulheres negras. Implica a afeição pelo negro (como uma comunidade imaginada) por meio de seu próprio corpo, e implica uma mudança na relação com a própria estética, na qual o "meu cabelo" torna-se "o cabelo dos negros", e por isso deve ser amado. Compreendemos a necessidade de autorreconhecimento como uma forma de reinvenção da mulher negra, visando restabelecer a autoestima.

Nilma Lino Gomes aponta que a construção política da estética e beleza negras é uma forma de emancipação em que "[...] os corpos negros se distinguem e se afirmam no espaço público sem cair na exotização ou na folclorização" (GOMES, 2011, p. 52). Segundo a autora,

[...] a partir do ano 2000 há uma politização da estética negra, via afirmação da corporeidade, diferente daquela realizada no final dos anos 70 e início dos 80 do século XX. O corpo negro e sua corporeidade se destacam na cena pública em meio a um processo tenso e ambíguo. Assistimos a uma maior presença de negros na mídia, porém, ainda acompanhada da denúncia feita pelo movimento negro referente ao persistente lugar de subalternidade. Surgem propagandas e peças publicitárias que adotam o negro como personagem central, porém, ainda com estereótipos. Há uma visualização e maior uso de penteados no estilo 'black power estilizado', do uso de dreads por jovens brancos da classe média, maior adesão ao uso das tranças pelas mulheres negras e brancas jovens e uma maior exposição do corpo negro nos eventos culturais. São processos de mudanças e de visibilidade da corporeidade negra em meio às tensões regulação-emancipação do corpo (GOMES, 2011, p. 48).

Munanga (1990) ressalta ainda a importância da busca da identidade pelos negros, dados os problemas específicos que enfrentam, de modo que tal busca "[...] funcionaria como uma espécie de terapia do grupo [... de modo que o] negro poderá despojar-se do seu complexo de inferioridade e colocar-se em pé de igualdade com outros oprimidos, o que é condição preliminar para uma luta coletiva" (MUGANGA, 1990, p. 116). No coletivo, o porquê da referência à ancestralidade se manifesta na busca por autoestima como forma de dar visibilidade à negação de direitos e preconceitos relacionados aos fenótipos negros. Essa

15 "[...] Perdemos o mundo e ganhamos o corpo. O interesse pelo corpo gera o desinteresse pelo mundo. [...] A preocupação com o mundo, ponto central da política desde a Antiguidade, foi substituída na modernidade pela preocupação com o homem, a descoberta de si mesmo [...]. Ao mesmo tempo e devido à sobrevalorização e ao enorme investimento simbólico que vem sofrendo nas últimas décadas, o corpo tornouse objeto de desconfiança, de receio, mesmo de desconforto: só aceitamos o corpo submetido a um processo de transformação constante. Não podendo mudar o mundo, tentamos mudar o corpo, o único espaço que restou à utopia, à criação" (ORTEGA, 2003, p. 73). Diferente de Ortega, o que se pode perceber aqui é que o cuidado com o corpo acaba por ser uma via de retorno ao mundo e ao debate público e não 0 resultado de sua evasão, estimulando assim as mulheres negras a perceberem na sociedade as tensões raciais. Certamente é possível dizer que enquanto uma mulher negra usa seu pente garfo em frente ao espelho, este mesmo espelho lhe sirva como uma janela para o mundo lá fora, embora, obviamente, nem sempre seja assim. Ouvimos relatos de mulheres que primeiro assumiram a estética afro, e em seguida passaram a participar de coletivos do movimento negro, outras, todavia, não chegaram a esse tipo de organização ou simplesmente não se interessam por qualquer tipo de debate político. 
elevação da autoestima visa tornar a mulher negra apta a exercer seu lugar na sociedade, enfatizando-se, todavia, suas habilidades empreendedoras.

Assim como pra mim é claro que a beleza negra é magníica em todas as suas singularidades, também é claro que a sociedade não permite (isso é histórico) que com isso seja massificado de forma que nós afrodescendentes nos tornemos livres dos estereótipos que nos perseguem, nos diminuem e nos impedem de avançar em direção a uma ocupação, que é nossa por direito, por direito como ser humano, direito de competir em igual condição, de ter coragem pra lutar... de ter autoestima mesmo! ${ }^{16}$

Ressaltamos que, no caso da corporeidade negra, a utopia apresenta-se corpórea, na reconciliação consigo, na vontade de trazer para o hoje a realização dos anseios políticos, ao encarar a estética como uma dimensão política, vendo nas caminhadas (de casa para 0 trabalho) pelas ruas uma forma de resistência à dominação. A identidade, como tema político, atualiza-se no corpo.

O caráter político da corporeidade negra acaba por atribuir, no interior do IDP, o dever político de amar-se. Isto aparece como o "real sentido" do empoderamento estético, configurando-se como uma forma política de afeição por si que considera o corpo belo tendo como referência a história e cultura afro-brasileira. Esse aspecto foi identificado em diferentes momentos da pesquisa, como, por exemplo, em momentos nos espaços voltados para bate-papo (como o Papo de Preta, evento voltado para encontro e troca de experiências) e nos conselhos apresentados em blogs. Todavia, esse estágio de amor próprio não se alcança por si só, é necessário encontrar apoio entre as demais companheiras, estimular-se mutuamente, para que superem o sentimento de inferioridade causado pela padronização estética. Daí a importância do que chamamos de Testemunho, o qual se caracteriza por um modo de compartilhamento de experiências que auxilia outras mulheres na construção de suas identidades. Exaltar a beleza de uma irmã negra é um modo de apoiá-la a seguir construindo sua identidade.

\section{TESTEMUNHO}

O Testemunho é um importante elemento na constituição da identidade no interior do IDP, e refere-se ao modo pelo qual se cria um discurso sobre a verdade no interior do coletivo, servindo como ponto unificador entre essas mulheres negras. O Testemunho, aqui analisado, dá-se como modo de inserção nesse universo relacionando-se à noção de memória:

A memória, onde cresce a história, que por sua vez a alimenta, procura salvar o passado para servir o presente e o futuro. [...] A memória é um elemento essencial do que se costuma chamar identidade, individual ou coletiva, cuja busca é uma das atividades fundamentais dos indivíduos e das sociedades de hoje, na febre e na angústia (LE GOFF, 1990, p. 477,).

O testemunho liga-se ao corpo na medida em que funciona como fundamentação para que se torne possível às mulheres negras narrar suas próprias experiências de vida, como narrativas dos corpos negros. Constantemente as mulheres narram suas histórias no IDP, de modo que há alguns curtos relatos no site $^{17}$ (onde algumas mulheres falam do modo pelo qual o coletivo elevou a autoestima e proporcionou a descoberta de sua identidade negra).

16 Extraído de um blog de uma das principais integrantes do Coletivo Das Pretas. Disponível em: <http://priscilagama.com.br/priscila-gamacompartilhe-empoderamento/>. Acesso em: 12 set. 2016.

17 Ver em: <https://www.daspretas.org/coletivo-das-pretas>. 
Destaca-se aí a importância para essas mulheres da partilha de suas experiências de vida na constituição de sua identidade como mulheres negras, o que se percebe na seguinte frase: "através da troca de experiências, [0 IDP] vem resgatando e reforçando a nossa identidade", ou ainda em expressões como "O Das Pretas me reconectou com meu orgulho negro" e "[...] me ensinou a valorizar a minha beleza como ela é". Encontram-se nesse ambiente segurança e companhia que fortalecem a caminhada dessas mulheres, como uma delas descreve "a possibilidade de caminhar no coletivo e saber que não estou sozinha me deixou mais forte". Isso se realiza por meio de um resgate da memória ancestral negra ("Conhecer nossa descendência"), que auxilia na autodescoberta identificada com o reconhecimento e aceitação de seus traços fenotípicos ("Meu cabelo crespo, meu nariz largo, minha pele [...] tudo isso é parte de quem sou e me orgulho demais") e possibilita a reconstrução da autoestima e resgate de sonhos ("Saber o que somos e onde queremos chegar para ajudar uns aos outros e alcançarmos nossos objetivos").

Nos Encontros Das Pretas e também nas reuniões do coletivo, as mulheres guardam momentos para compartilharem suas narrativas pessoais. Como exemplo, temos a apresentação do trabalho de uma Das Pretas, que é trançadeira, e que, por uma espécie de testemunho público, afirmou que realizar o trabalho elevou sua autoestima. 0 momento era aberto para que qualquer pessoa presente testemunhasse sua experiência. Vale ressaltar que as atividades realizadas nesse espaço tiveram início com uma dinâmica para "quebrar o gelo", com a finalidade de que todos os presentes tocassem os cabelos uns dos outros para "verem que não é duro", mas "macio". Ressaltou-se aí que "o cabelo é algo muito nosso". Tocar nos cabelos uns dos outros implicava, assim, em um rompimento de limites.

Uma vez que o testemunho oferece um quadro de compreensão da realidade, a testemunha o testifica pela opressão sentida na pele. Este garante assim que sua história não é única, retira-lhe da solidão de sua própria dor e permite-lhe falar do assunto. Por outro lado, o testemunho necessita de que pessoas tenham passado pelo que se afirma. Desse modo, 0 que chamamos aqui de Testemunho está ligado às marcas de dor vividas nos corpos dessas mulheres negras.

Além do auxílio mútuo e da presença dos testemunhos nos encontros do coletivo, merecem destaque nas construções discursivas do grupo as personagens representativas na sociedade que influenciam/relativizam os padrões de beleza vigentes. Isso nos levou a observar o que o IDP chama de representatividade e que nos ofereceu elementos para a construção da categoria Visibilidade, ou seja, a presença do corpo negro em lugares de destaque na sociedade.

\section{VISIBILIDADE}

Com a categoria Visibilidade estamos considerando as menções realizadas no Das Pretas no que se refere à importância da presença de mulheres negras nos espaços de protagonismo e poder da sociedade. Isso aparece no coletivo não somente como a constatação de uma necessidade, mas ainda como incentivo aos empreendimentos das mulheres negras e afirmação de sua negritude onde quer que estejam inseridas. Se o Testemunho possui um caráter que enfatiza a dor, a Visibilidade apresenta uma característica inversa ao apontar outras possibilidades de inserção social. Trata-se de enfatizar as histórias de sucesso dos negros na 
sociedade visando à construção de novos modelos corporais que gerem inspiração. Assim, é uma forma de dar destaque aos negros em movimento, a presença do corpo negro em lugares que antes eram vistos como hostis.

Isso nos remete às pressões vivenciadas na constituição da subjetividade do negro e da negra, marcas profundas causadas pela construção identitária que toma como referência 0 branco. $O$ racismo à brasileira e sua religião do branqueamento forçara rituais variados de embelezamento, desencadeando inúmeras formas de labor sobre si em busca da beleza inalcançável, porque buscava converter o corpo negro no corpo branco, seu Ideal de Ego ${ }^{18}$ :

Sob quaisquer nuances, em qualquer circunstância, branco é o modelo a ser escolhido. Escolha singular, fixada à revelia de quem apenas deve a tal modelo configurar-se. [...] a primeira regra básica que ao negro se impõe é a negação, 0 expurgo de qualquer "mancha negra" (SOUZA, 1983, p. 34).

Assim, enfatizando os corpos negros visíveis, busca-se reconfigurar esse Ideal de Ego, tornando-se sua própria referência. A ideia de representatividade (visibilidade/protagonismo) localizada aqui se sustenta na noção de empoderamento, operando um fortalecimento que, ao verem-se representados (nos produtos, modelos e personalidades de destaque na sociedade), sentem-se motivados a empreender e acreditar em si e em outros negros. As biografias de negras bem-sucedidas auxiliam na narração das identidades individuais, assim como a estas se direcionam. Além disso, ressaltam a abertura para novas possibilidades de sua inserção no mercado de trabalho (e também de consumo). Tais argumentos eram constantemente enfatizados nas palestras do coletivo e na Marcha do Orgulho Crespo, organizada em Vitória pelo IDP.

A luta antirracista promulgada pelo IDP busca um meio de realização controverso, justamente neste ponto: a ênfase no empoderamento da mulher negra na sociedade por meio do consumo. Essa ideia conjuga-se com a de empreendedorismo e de consumo, sugerindo que ser "empoderado" implique consumir e lucrar.

No entanto, a relação do IDP com o mercado não deve ser compreendida apenas na perspectiva da visibilidade e lucratividade. Sua compreensão acerca do que chamam de consumo negro resgata 0 ideal de solidariedade negra, buscando fomentar a lealdade entre negras e negros, ainda que por meio do mercado. Importa-nos, portanto, observar o Afroconsumo ou o que o coletivo chama de Consumo Negro (estratégia de economia criativa ${ }^{19}$ que visa ao empoderamento econômico dos negros), no qual trocas simbólicas se realizam na busca por conceder autonomia financeira e emocional às produtoras e consumidoras.

\section{AFROCONSUMO}

Os produtos comercializados pelas mulheres do IDP advêm de empreendedoras negras, e se direcionam principalmente, mas não somente, para o público afro. São brincos, blusas, vestidos, cremes de pele, sabonetes e outros elementos próprios ao cuidado estético

\footnotetext{
18 "[...] O ideal de Ego é do domínio do simbólico. Simbólico quer dizer articulação e vínculo. Simbólico é o registro ao qual pertencem a Ordem simbólica e a Lei que fundamenta esta ordem. O Ideal do Ego é, portanto, a instância que estrutura o sujeito psíquico, vinculando-o à Lei e à Ordem. É o lugar do discurso. O Ideal do Ego é a estrutura mediante a qual 'se produz a conexão da normatividade libidinal com a cultural'" (SOUSA, 1983, p. 33).

19 "De acordo com a Organização das Nações Unidas (ONU) as atividades econômicas criativas encontram-se no cruzamento das artes, da cultura, dos negócios e da tecnologia, compreendendo o ciclo de criação, produção e distribuição de bens e serviços que utilizam 0 conhecimento e a criatividade como seus principais inputs" (SERRA, 2014, p. 357).
} 
feminino, produzidos de forma artesanal. Além disso, palestras, poesias, zines, vídeos e outros produtos culturais de mulheres negras são promovidos pelo IDP.

A produção e o consumo são vistos como meio para ascensão social e conscientização da causa negra. Conforme observamos no discurso Das Pretas, por meio do afroconsumo se faz menção ao passado, como referência à ancestralidade; fortalecimento no presente, por seu significado social (enriquecer a produtora negra); e futuro, pela garantia de melhores condições no mercado a partir da abertura de novos nichos econômicos, possibilitando maior empreendimento.

Esta categoria relaciona-se à corporeidade no ponto em que o coletivo denuncia a exclusão para com os negros, por parte do mercado, principalmente os mais melaninados, justamente por não criar produtos voltados especificamente para eles, e propõe caminhos de entrada no mercado por meio do reconhecimento entre consumidores e afroempreendedores ${ }^{20}$. Trata assim como importante o reconhecimento da presença/ausência do corpo negro no mercado, tomando-o como signo de resistência e denúncia do racismo presente nas estruturas sociais.

Desse modo, sugerem que seja necessário aos negros repensarem seu modo de consumo. Conceituam assim, o consumo preto como "um irmão que produz pensando no outro e o outro irmão que consome, empoderando o um" (DIÁRIO DE CAMPO, 2016). Por essa troca, um negro produz produtos específicos para negros, o Das Pretas compreende que mais que a oferta de um produto, existe uma ação política inserida que leva em consideração um setor da sociedade desprestigiado pelo mercado. O consumidor, por sua vez, dá sentido ao ato de consumir ao valorizar o produtor e solidarizar-se com ele em seu trabalho.

A estratégia de consumo visa diminuir os custos para o afroempreendedor, enquanto oferece produtos pensados especificamente para o público negro (embora não sejam somente negros que consumam os produtos vendidos na loja colaborativa $\left.{ }^{21}\right)$. A narrativa que se constrói, no fortalecimento da história dessas mulheres negras, as conduz a agir em fidelidade a seu próprio grupo, a olhar para um setor da sociedade que comumente é esquecido. Desse modo, aponta para uma reflexão acerca do acesso aos produtos disponíveis na sociedade de consumo, e até mesmo a questionar se é correto ou não consumir determinados produtos. Nesse sentido, ao narrar a história do povo negro, à qual tais mulheres vinculam-se por seus testemunhos pessoais, coloca-se o consumo como uma questão ética. Alguns apontamentos são importantes em relação a esse tema.

Ao pensarmos a afeição por si, nos deparamos com uma tensão entre os conselhos difundidos no coletivo que se apresenta no modo como algumas questões referentes à estética são tratadas, tendo que continuamente exercer-se um tipo de aconselhamento que pode ser restrito à esfera individual. Embora a referência à vida pública, por vezes, se apresente

20 O Coletivo faz uma distinção entre empreendedores afros e afroempreendedores. Os primeiros são todos os negros em seus ofícios comuns, voltados para o atendimento ao público em geral, cujo produto de seu trabalho não é específico para negros (pedreiros, médicos, advogados, etc.). Os afroempreendedores, por sua vez, produzem pensando nas particularidades do público negro (embora ressaltem que os não negros podem também consumi-los). Sobre essa posição, ver em: $\langle$ https://www.youtube.com/watch?v=0uO5v1qJdA0\&t=322s $>$. Acesso em: 16 nov. 2016. E também em: <http://www.gazetaonline.com.br/noticias/cidades/2016/11/pretas-e-empresarias-conheca-os-espacosvoltados-para-o-empreendedorismo-negro-1013996746.html>. Acesso em: 10 dez. 2016.

21 Uma das entrevistadas relata que "[...] a galera vem procurar mais por causa disso mesmo. Por causa das estampas. Isso é o que mais [...] me impressiona. Dá muita gente que não é negra, comprando também. Tanto para presente, quanto pra consumo próprio. Porque acha bonito. Mas tem que pensar que nosso maior público vem por causa dessa questão. Também não acha em outro lugar. Agora até que tá na moda, eventos vendendo brincos afros, mas roupa, ainda é bem difícil". Embora ideologicamente o coletivo vise atingir o público negro, grande parte das consumidoras não são negras. 
como constituindo um lugar no qual as outras mulheres fortalecem cada uma individualmente, motivando-as a seguir e superar, por exemplo, o período de transição capilar (do cabelo alisado para o crespo ou cacheado).

Todavia, ao mesmo tempo, ainda que não de forma muito elaborada, é possível notar uma postura de rejeição ao empoderamento "meramente estético", a certa tendência de valorização da estética feminina negra presente na sociedade de consumo. Isto é ambíguo no discurso do Das Pretas, visto que também louva de modo indiscriminado a atenção do mercado devotada às negras e negros. Assim, é possível encontrar no Das Pretas recomendações do mesmo tipo que nos apresenta Bauman (2001) ao nos falar do amor de $s^{22}$, principalmente, quando se ressalta a importância das representações na mídia e nos conselhos para empoderarse a si mesma, direcionando os conselhos à esfera privada.

Coadunam-se a esse discurso os slogans dos salões especializados em cachos, e a referência constante se faz no retorno ao "natural", que se torna possível por meio da utilização de produtos especializados. Uma das empresas parceiras do Das Pretas usa em suas propagandas as frases: "cuidado e naturalidade para cabelos crespos", além de "seus cabelos têm poder" e "sua beleza liberta" (poder e liberdade são aqui ligados aos cuidados com o corpo).

Enfatiza-se a virtude da coragem de assumir publicamente a identidade, na qual "apropriar-se de si" é um ato de enfrentamento, de denúncia, ou seja, um ato de autoafirmação social. Ao mesmo tempo, isso se apresenta como uma chamada potente ao consumidor. Os conselhos que ouvimos no IDP apresentam certa ambiguidade, sendo ora voltados para 0 indivíduo, responsabilizando-o por sua própria felicidade e amadurecimento na constituição de sua identidade, ora criticando os usos individuais da estética negra ao falarem contra 0 empoderamento "meramente estético". Todavia, é possível encontrar também recomendações do mesmo tipo, principalmente quando se ressalta a importância das representações na mídia e nos conselhos para seu próprio empoderamento. Nesses casos, não se fazem as mesmas críticas que direcionam a outras jovens que estariam apenas seguindo certo modismo de época.

Esse "amor de si" presente, em alguma medida, nos discursos Das Pretas apresenta a ousadia de romper as normas, suscitando a prontidão para fazê-lo. Nessa direção, para estar apto é preciso estar atento aos conselhos e possibilidades disponíveis no mercado. Ferguson, apud Bauman (2001), diz que há uma relação entre a autoexpressão por meio dos bens de consumo e as noções de gosto e discriminação, numa relação em que o querer substitui 0 desejo como força motivadora do consumo. Você pode ser o que quiser ser na sociedade contemporânea, contanto que consuma. Isso implica que, juntamente com a absorção do discurso periférico pelo mercado, advém a maior visibilidade e aceitação social. Dilui-se a agonia da resistência na "tolerância" do consumo.

Por fim, importa-nos pensar também na relação defendida pelo IDP pela maior inserção de negros no comércio, como consumidores, o que se dá pela construção de um nicho de consumo étnico, assim como de empreendedores preparados para oferecer produtos de qualidade a fim de darem maior visibilidade às pautas dos negros. Esse discurso tece poucas

22 O sociólogo situa esse amor de si como expressão de um labor exercido sobre o próprio corpo, considerando-o propriedade do indivíduo e garantindo-Ihe a glória pelo sucesso ou a culpa pelo fracasso deste cuidado. Fundamental é perceber a distinção que Bauman faz entre os líderes presentes na modernidade sólida e os atuais conselheiros. A principal distinção entre essas duas figuras se dá pelo fato de que o primeiro criava pontes entre o bem individual e o bem coletivo, enquanto o segundo direciona seus conselhos para a esfera privada e não ousa retirar daí o seu pé. 
críticas à estrutura social. Além disso, gera tensões entre o periférico e a ideia de produção de uma cultura de centro, que seja reconhecida não como "artesanato", mas como produto pronto "para o investimento". A noção de fidelidade entre produtores negros e consumidores apresenta-se como um desafio para os afroempreendedores (pequenos ou grandes). Todavia, a busca por ganhar as consciências (uma batalha assumida pelo coletivo) não será realizada apenas por pequenas afroempreendedoras, mas, principalmente, e com maior poder de alcance, pelas grandes empresas consolidadas. Assim, o afroconsumo acaba por fornecer uma capa moral para a mesma estrutura de distribuição dos bens do capitalismo. A ideia de enriquecer seu irmão rapidamente passa da artesã de poucos recursos para a uma corporação cosmética, bastando a presença de uma modelo negra na capa da revista.

\section{CONSIDERAÇÕES FINAIS}

Entendemos que a conjugação dos elementos descritos nas categorias aqui citadas seja capaz de fornecer uma visão acerca da corporeidade promulgada pelo IDP, que, a saber, tem-se o corpo como um elemento culturalmente concebido, de modo que sua compreensão não é somente por meio de seus traços fenotípicos, mas também por suas representações nas mídias sociais e no mercado. Considera-se, ainda, a constituição da autoestima da mulher negra em referência à sua relação com a própria imagem, propondo a reconciliação com esta por meio do reconhecimento da história ancestral negra, à qual se unem as mulheres, principalmente pela constatação "à flor da pele" de que as marcas do preconceito racial continuam presentes em suas histórias.

Através da categoria Autorreconhecimento, notamos que a construção da subjetividade promulgada pelo IDP configura-se tendo como imperativo político a afirmação da estética negra como a de um povo, de modo que a comunidade negra passa a constituir-se como referencial para a compreensão da própria corporeidade. Isso nota-se ainda pelo que caracterizamos como Testemunho, e que cada mulher tem a possibilidade de tornar pública sua experiência pessoal de reconciliação com a própria imagem, encontrando solidariedade e acolhimento por parte das demais. O IDP aposta ainda na presença deles em lugares de visibilidade social, como elemento importante para reforçar a identidade destas mulheres e produzir, de certo modo, orgulho de seus corpos, buscando reformular assim seus ideais de Ego, ou seja, produzindo uma sensibilidade corporal possível. Por fim, conectando esses processos, reforçase o empoderamento econômico pela troca de produtos voltados para mulheres negras, e revelam-se tensões entre o poder econômico e ideológico.

No limiar entre o empoderamento social e a apreensão mercadológica da imagem negra, o IDP configura-se como lugar por onde circulam valores diversos, ora promovendo novas formas de sentir o mundo e existir, ora reproduzindo valores e relações com o próprio corpo que se assemelham ao que se encontra nos shoppings e academias de musculação. Se o IDP nos lembra que brincos não são apenas brincos, não deve esquecer-se ainda que seus usos estejam em permanente tensão. 


\section{REFERÊNCIAS}

BAUMAN, Zygmunt. Modernidade Líquida. Rio de Janeiro: Zahar, 2001.

DISKIN, Lia. Vamos ubuntar? Um convite para cultivar a paz. Brasília: UNESCO, Fundação Vale, Fundação Palas Athena, 2008.

DOMINGUES, Petrônio. Movimento da negritude: uma breve reconstrução histórica.

Mediações: Revista de Ciências Sociais, v. 10, n.1, p. 25-40, jan./jun. 2005.

GOMES, Nilma Lino. Corpo e cabelo como símbolos da identidade negra. Disponível em: <http://www.acaoeducativa.org.br/fdh/wp-content/uploads/2012/10/Corpo-e-cabelo-comos\%C3\%ADmbolos-da-identidade-negra.pdf> Acesso em: 05 jan.2017,

GOMES, Nilma Lino. Alguns termos e conceitos presentes no debate sobre relações raciais no Brasil: uma breve discussão. In: BRASIL. Educação Anti-racista: caminhos abertos pela Lei federal no 10.639/03. Brasília, MEC, Secretaria de Educação Continuada e Alfabetização e Diversidade, 2005. p. $39-62$.

GOMES, Nilma Lino. Movimento Negro, saberes e a tensão regulação-emancipação do corpo e da corporeidade negra. Contemporânea:Revista de Sociologia da UFSCar, n. 2, p. 37-60, 2011.

KERN, Gustavo da Silva. Biopoder, biopolítica e o discurso eugenista produzido no Brasil. In. SIMPÓSIO NACIONAL DE HISTÓRIA, 28.1995. Anais... Florianópolis, 1995. Disponível em: < http://www.snh2015.anpuh.org/resources/anais/39/1434307765 ARQUIVO TextoFinalAnpuh2015. pdf>. Acesso em: 22 jan. 2017.

LE GOFF, Jacques. História e memória. Tradução Bernardo Leitão [et al.]. Campinas: Editora da UNICAMP, 1990. (Coleção Repertórios).

MAGNANI, José Guilherme Cantor. Etnografia como prática e experiência. Horizontes Antropológicos, v. 15, n. 32, p. 129-156, jul./dez. 2009.

MATTOS, Ivanilde Guedes de. Estética Afro-diaspórica e o empoderamento crespo. Pontos de Interrogação: Rev. do PPG Crítica Cultural, v. 5, n. 2, p. 37-53, jul/dez, 2015.

MUNANGA, Kabengele. Negritude Afro-Brasileira: Perspectivas e Dificuldades. Revista de Antropologia, n.33, p. 109-117, 1990.

MUNANGA, Kabengele. Rediscutindo a mestiçagem no Brasil: Identidade nacional versus identidade negra. Petrópolis, RJ: Vozes, 1999.

MUNANGA, Kabengele. Uma abordagem conceitual das noções de raça, racismo, identidade e etnia. In: SEMINÁRIO NACIONAL RELAÇÕES RACIAIS E EDUCAÇÃO, 3. 2003. Disponível em: <http://www.geledes.org.br/wp-content/uploads/2014/04/Uma-abordagem-conceitualdas-nocoes-de-raca-racismo-dentidade-e-etnia.pdf>. Acesso em: 16 jan. 2017.

MUNANGA, Kabengele. Negritude, Usos e Sentidos. Belo Horizonte: Autêntica 2012. (Coleção Cultura Negra e Identidades).

ORTEGA, Francisco. Práticas de ascese corporal e constituição de bioidentidades. Cadernos de Saúde Coletiva, v.11, n.1, p. 59-77, 2003. 
SERRA, Neusa. Economia criativa: da discussão do conceito à formulação de políticas públicas. Revista de Administração e Inovação, v. 11, n.4, p.355-372, out./dez. 2014.

SOUSA, Neusa Santos. Descobrir-se negro: as vicissitudes da identidade do negro brasileiro em ascensão social. Rio de Janeiro: Graal. 1983.

\section{Apoio financeiro:}

